\title{
Chirality, Rigidity, and Conjugation: A First-Principles Study of the Key Molecular Aspects of Lignin Depolymerization on Ni-Based Catalysts
}

\author{
Qiang $\mathrm{Li}^{*}{ }^{\circ}$ and Núria López*⿻一丿 \\ Institute of Chemical Research of Catalonia (ICIQ), The Barcelona Institute of Science and Technology, Avgda. Països Catalans 16, \\ 43007 Tarragona, Catalonia, Spain
}

Supporting Information

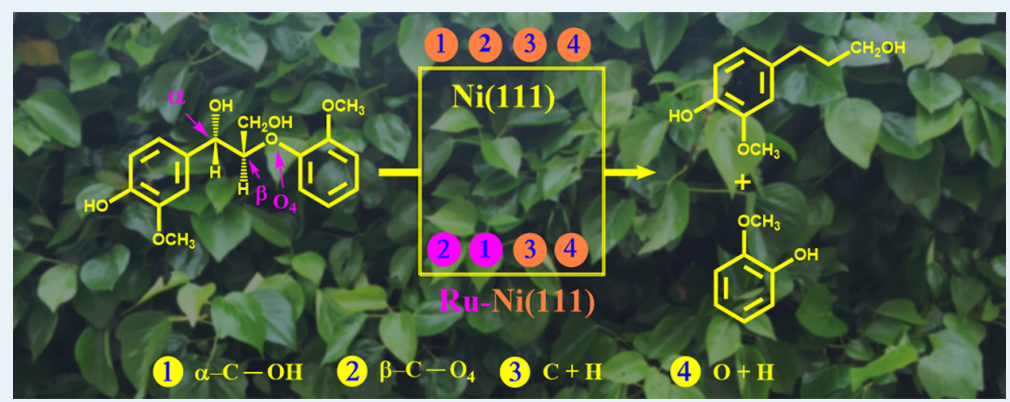

ABSTRACT: Efficient lignin depolymerization is crucial for achieving a positive economical return in biorefineries. However, because of the complex cross-polymerized network formed by the aromatic lignols, catalysts that can work at low temperatures perform insufficiently in terms of both activity and selectivity. Recently, Ni-based catalysts have been reported to exhibit a superior catalytic behavior in lignin valorization, but the mechanism of the depolymerization remains unclear. In this study, we employed density functional theory to investigate lignin decomposition on pure and $\mathrm{Ru}$-doped $\mathrm{Ni}(111)$ surfaces to unravel the key issues that limit performance. The reaction network was screened by using complex coniferyl dimer models containing different stereocenters to simulate the most abundant $\beta$-O-4 linkages in lignin, thus presenting a better representation of the complexity of the parent compound. Our results show that on nickel, both adsorption geometries and the preferred reaction paths are different depending on the chirality of the dimer reactants. In addition, the rigidity of the $\beta$-O- 4 link is also responsible for the reactivity found. Finally, the presence of small amounts of $\mathrm{Ru}$ on the surface simplifies the reaction as they act as preferential points for $\beta-\mathrm{O}-4$ bond cleavage via the weakened $\mathrm{C}-\mathrm{O}$ bond that is induced by increasing metal-O bond strength. KEYWORDS: lignin, DFT, $\beta-\mathrm{O}-4$, chirality, rigidity, conjugation, $\mathrm{Ni}, \mathrm{Ru}$

\section{INTRODUCTION}

Lignin is a complex cross-linked phenolic polymer that widely exists in the cell walls and supports plants via its strength and rigidity. It is one of the main components in lignocellulosic biomass resources, accounts for $15-30 \%$ of the weight, and stores $40 \%$ of the energy. ${ }^{1}$ However, because of its high stability, efficient depolymerization methods are lacking, ${ }^{2-4}$ and $98 \%$ of the lignin produced by the paper and pulp industry was considered a low-value material and burned for heating at the beginning of the 21st Century. ${ }^{5}$

In the near future, because of the depletion of oil reserves, lignin will be seen as a new source of the major aromatic compounds (such as the BTX fraction of benzene, toluene, and the three xylene isomers $)^{6}$ or will directly provide some synthetic intermediates that are used in the industry. Altogether, the derived platform chemicals could be used as renewable materials in the polymer industry with great potential in food and medical applications and as carbon fibers to name just a few. ${ }^{7,8}$ However, the optimal processing of lignin is far from being realized. Hence, developing catalysts with high efficiency and selectivity for depolymerization is the key to allowing application in high value-added chemicals and improving the economics of the biorefinery process. ${ }^{9-11}$

One of the added difficulties in the chemical treatment of lignin is its variable composition when different raw materials, such as hardwood, softwood, and grass, are fed in the bioconfinery process. ${ }^{3}$ The proportions of the monomeric units and linkages depend on the origin of lignin. ${ }^{3}$ The most common monolignols (see Figure 1) from the depolymerization are p-coumaryl $(\mathrm{H})$, coniferyl $(\mathrm{G})$, and sinapyl alcohols $(S)^{12}$ and different linkage topologies connecting these monomers have been identified: $\beta-\mathrm{O}-4, \beta-5, \alpha-\mathrm{O}-4, \beta-\beta, 5-5$, 4-O-5, $\beta-1$, and others (see Figure S1). The most representative linkage is $\beta-\mathrm{O}-4$, which accounts for $43-50 \%$ in softwood and 


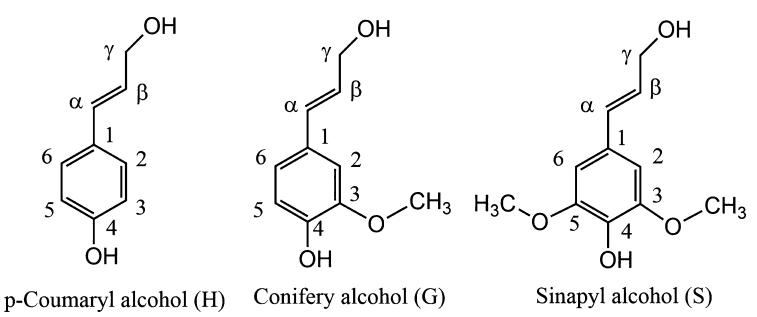

Figure 1. Structures of three lignin monomers.

$50-65 \%$ in hardwood and happens to be the most labile. Therefore, breaking the $\beta$-O- 4 bond is the highest priority in catalytic depolymerization and valorization processes.

Some compounds have been proposed as homogeneous depolymerization catalysts, but heterogeneous catalytic lignin transformation has advantages in flow processing, ${ }^{13,14}$ production separation, and catalyst recycle ability and is suitable for large industry scale processes. Comprehensive reviews of the advances in the area were presented by Calvo-Flores, Zakzeski, ${ }^{2}$ Zhang, ${ }^{3}$ and Behling et al., ${ }^{4}$ focusing on: (i) the basic lignin compositions, (ii) various lignin valorization approaches in both heterogeneous and homogeneous systems, and (iii) wide potential uses of its products in chemicals, fuels, and materials. A majority of catalysts investigated are transition metal-based, including those based on $\mathrm{Mn}, \mathrm{Co}, \mathrm{Ni}, \mathrm{Ru}, \mathrm{Pd}$, and $\mathrm{Pt}$. Multicomponent catalysts like transition metal $(\mathrm{Ti}, \mathrm{Mo}, \mathrm{Nb}$, and $\mathrm{W}$ ) nitrides have been applied by Chen et al., ${ }^{15}$ and $\mathrm{Ti}-\mathrm{N}$ was identified as a promising catalyst for partial lignin depolymerization. The titanium-nitride-nickel catalyst (TiN$\mathrm{Ni}$ ) has also been used under mild reaction conditions by Molinari et al. ${ }^{16}$ and exhibited a performance comparable to that of the Raney Ni catalyst, which is a well-known catalyst for hydrogenation processes.

Among the transition metal catalysts, $\mathrm{Ni}$ exhibits superior activity in aryl-alkyl bond activations in lignin hydrogenolysis, as the aromatic moieties are kept intact in both homogeneous ${ }^{14}$ and heterogeneous ${ }^{17}$ processes. Still, Ni-based catalysts exhibit poor activity below $120{ }^{\circ} \mathrm{C},{ }^{18}$ and thus, improvements in performance to reduce working temperatures are desirable. By combining $\mathrm{Pd}$ and $\mathrm{Ni}$ into a bimetallic nanoparticle catalyst, Zhang et al. ${ }^{19}$ observed a remarkable catalytic enhancement compared with the results with only $\mathrm{Ni}$ and $\mathrm{Pd}$. A previous study by Yan et al. ${ }^{18}$ showed that a Ni-Ru bimetallic catalyst exhibits excellent behavior in aqueous lignin hydrogenolysis, compared with that of $\mathrm{Ni}-\mathrm{Rh}$ and $\mathrm{Ni}-\mathrm{Pd}$ catalysts. Both studies show the synergistic effects of two metals.

Density functional theory (DFT) approaches to understanding the reaction network for depolymerization are rather scarce. By combining DFT calculations and experiments, Wang et al. ${ }^{20}$ investigated the $\beta$-O-4 bond scission on $\mathrm{Pd}(111)$. In this study, the lignin model was represented by 2-phenoxy-1phenylethanol and its $\beta-\mathrm{O}-4$ bond cleavage was studied. Recently, adsorption structures of the same simple model on $\mathrm{Ni}(111)$ and $\mathrm{a} \mathrm{MoS}_{2}$ surface have been optimized. ${ }^{21}$ In addition, Hamou et al. ${ }^{22}$ studied the adsorption and decomposition mechanism of lignin on $\mathrm{Pt}(111)$ by using 2phenoxyethanol. The use of surrogates has provene to be interesting for small molecules; ${ }^{23}$ however, lignin models employed in theoretical and experimental studies are exceedingly too simple to fully represent and describe the real lignin adsorption configurations. ${ }^{4}$ For example, numerous lignin linkages with stereocenters are formed between monolignols, ${ }^{24}$ and the steric effect of methoxy or other groups in the meta and para aromatic substitution positions would also have an impact on the interactions between molecules and the surface and further affect the reaction network. ${ }^{25}$

Besides, to improve the catalyst design, a further understanding of the reaction process at the atomic level is needed. Knowledge of the depolymerization mechanisms of lignin on the Ni-based catalysts is lacking. This is due to several factors, including: (i) the large size of lignin that has prompted the use of small surrogates ${ }^{4}$ that does not account for key aspects like the chirality of the linkers, the rigidity of the molecules, and the conjugation of intermediates, (ii) the complex reaction networks that involve various products, and (iii) the variety of metal catalysts and the complexity of advanced materials like TiN-Ni. ${ }^{16}$ In view of these fundamental complexities, we have employed DFT calculations on slab models representing the simplest of these materials ( $\mathrm{Ni}$ and $\mathrm{Ru}$-doped $\mathrm{Ni}$ ) but considered large molecular surrogates that have stereocenters [dimers $\left(\mathrm{C}_{17} \mathrm{H}_{20} \mathrm{O}_{6}\right)$ of the most abundant monolignols coniferyl alcohol $(\mathrm{G})]$ and an extensive reaction network that accounts for many of the potential transformations taking place. Our results first reveal the effects of the stereocenters on the decomposition mechanism and the synergistic effects on the $\mathrm{Ru}$-doped Ni catalyst, thus providing guidelines for the design of the incoming catalysts.

\section{COMPUTATIONAL DETAILS}

In this work, slab model calculations were performed by using the Vienna Ab-initio Simulation Package (VASP). ${ }^{26,27}$ The exchange and correlation energies were obtained via the PBE functional. ${ }^{28}$ We also included van der Waals (vdW) corrections by applying the Grimme's DFT-D2 method, ${ }^{29,30}$ with the $C_{6}$ reparametrized by our group. ${ }^{31}$ The inner electrons were represented by projector augmented wave (PAW) pseudopotentials with cutoff energies of $450 \mathrm{eV}^{32,33}$ The Brillouin zone was sampled by a $\Gamma$-centered k-point mesh generated through the Monkhorst-Pack method. ${ }^{34}$ The calculated $\mathrm{Ni}$ and $\mathrm{Ru}$ lattice parameters of 3.517 and $2.712 \AA$, respectively $(c / a=1.581)$, agree well with previous experimental results of 3.524 and $2.706 \AA$, respectively $(c / a=$ $1.582)^{35}$

For small species such as ethylene glycol (EG), $\mathrm{H}_{2} \mathrm{O}, \mathrm{H}, \mathrm{CO}$, $\mathrm{O}$, and $\mathrm{OH}$, adsorptions were optimized on a $p-(3 \times 3)$ supercell with four layers and $\Gamma$-centered $5 \times 5 \times 1 \mathrm{k}$-point sampling was used. The energies are listed in Table S1. In larger slab optimizations, the $\mathrm{Ni}(111)$ and $\mathrm{Ru}(0001)$ surfaces were modeled by a four-layer slab with $p$ - $(7 \times 4)$ supercells, the two uppermost layers were fully relaxed, and the remaining bottom atoms were fixed to the bulk distances. Then, the atoms in the last bottom layer were removed and the three remaining layers were fixed and used for adsorption and transition state calculations. As the adsorption was performed on one side of the slab, a $15 \AA$ thick vacuum region was set between each slab to prevent their interaction, and dipole correction along the $z$ direction $^{36}$ was also applied to eliminate the spurious contributions arising from the system's asymmetry. To reduce the computational burden, we used $\Gamma$-point sampling to obtain the adsorption and transition state structures first. Then, they were taken as the initial inputs for reoptimization via the denser $\mathrm{k}$-point mesh of $2 \times 3 \times 1$. Because of the large sizes of slabs and adsorbates, the level of accuracy in our model has been tested by comparing the adsorption and reaction energies on a three-layer slab $\mathrm{Ni}(111)$ surface with those on the four-layer 


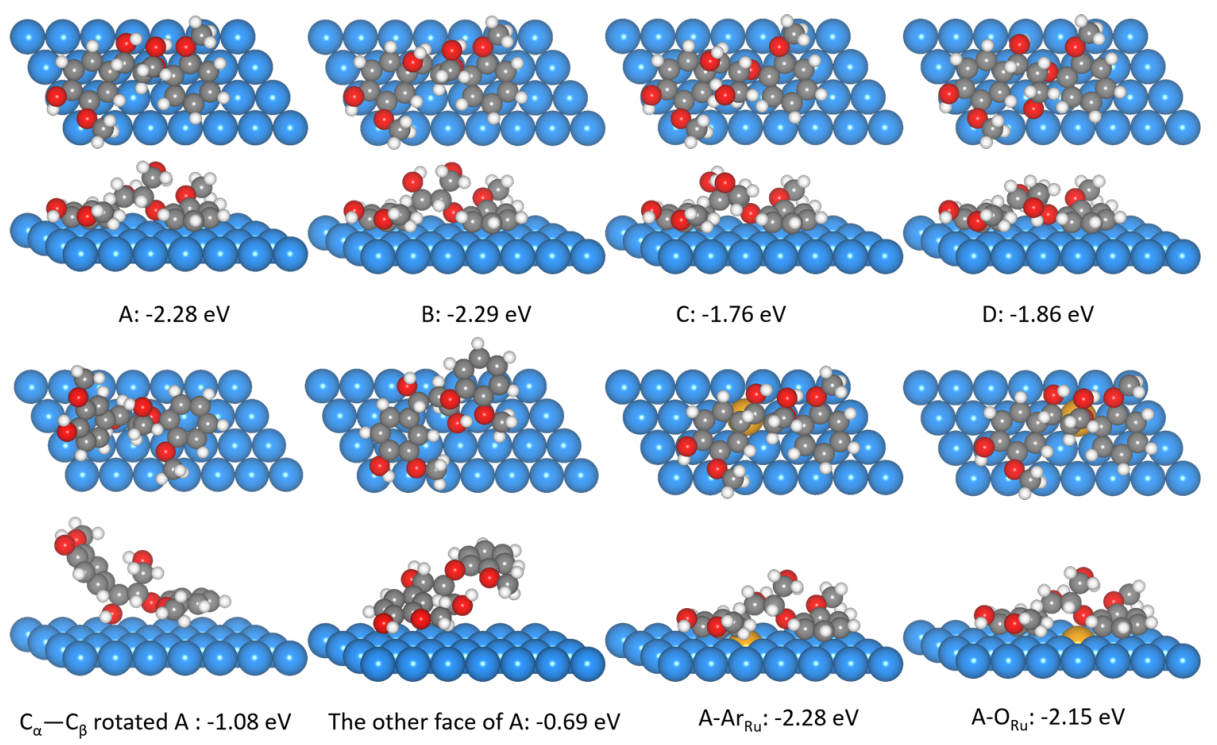

Figure 2. Adsorptions of four $\beta$-O-4 bond isomers, two structures from the $\mathrm{A}$ isomer after rotation of the $\mathrm{C}_{\alpha}-\mathrm{C}_{\beta}$ bond and using the other face on the $\mathrm{Ni}(111)$ surface. $\mathrm{Ar}_{\mathrm{Ru}}$ and $\mathrm{O}_{\mathrm{Ru}}$ are two surface $\mathrm{A}$ isomer structures on the $\mathrm{Ru}-\mathrm{Ni}(111)$ surface. $\mathrm{Ni}, \mathrm{Ru}, \mathrm{C}, \mathrm{H}$, and $\mathrm{O}$ atoms are colored blue, yellow, gray, white, and red, respectively.

\section{Scheme 1. Reaction Network of Isomer A Depolymerization and Hydrogenation on the Ni(111) Surface ${ }^{a}$}

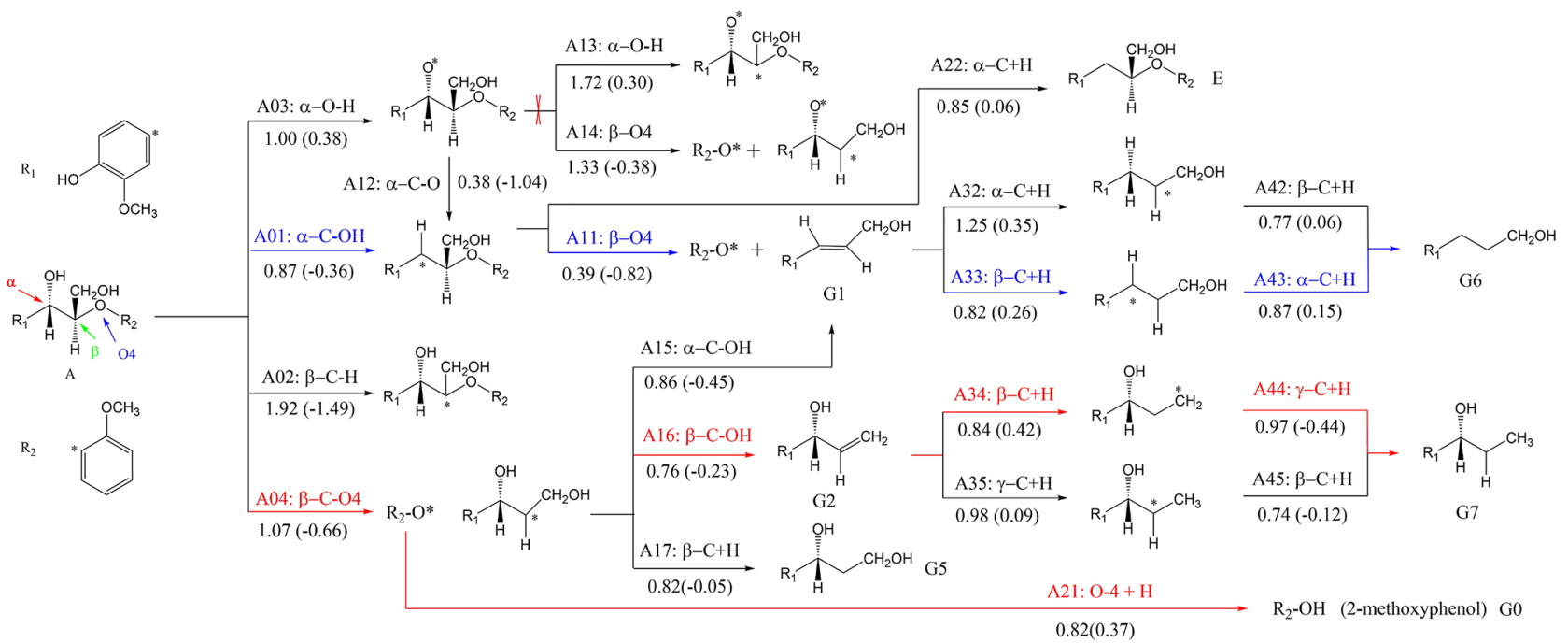

${ }^{a}$ Blue and red pathways are preferred reactions from $\alpha$-C and $\beta$-C sides, respectively.

slab. The tested results are listed in Tables S2 and S3. The adsorption energy differences of four $\beta$-O-4 models and 10 depolymerization products are in the range of $0.14-0.23 \mathrm{eV}$, which is within the traditional accuracy of the GGA-PBE level we used. ${ }^{37}$ Eight reactions on two slabs were tested, and their reaction energy differences are from 0.00 to $0.05 \mathrm{eV}$, demonstrating the reliability and accuracy by using a threelayer slab to describe the surface reactions.

We employed the climbing image nudged elastic band method (CI-NEB), ${ }^{38}$ the improved dimer method (IDM), ${ }^{39}$ and the quasi-Newton algorithm to locate and optimize the transition states in the potential surfaces. The thresholds were $10^{-5} \mathrm{eV}$ and $0.03 \mathrm{eV} / \AA$ for electronic and ionic relaxations, respectively. The saddle point nature of the transition states was assessed by the calculation of the numeric Hessian with a step of $0.02 \AA$ and its diagonalization that rendered a single imaginary frequency.

All molecules in the gas phase were relaxed in a box with dimensions of $20 \times 20 \times 20 \AA^{3}$. Four coniferyl alcohol dimers with different chiralities [named A $(\alpha-\mathrm{S}, \beta-\mathrm{S}), \mathrm{B}(\alpha-\mathrm{R}, \beta-\mathrm{S}), \mathrm{C}$ $(\alpha-\mathrm{R}, \beta-\mathrm{R})$, and $\mathrm{D}(\alpha-\mathrm{S}, \beta-\mathrm{R})]$ were used as the lignin $\beta$-O-4 model in this study, as shown in Figure 2 and Figure S2. The aliphatic side chain on the right aromatic moiety was removed to reduce the length of the molecule and also the model surface length along the $y$ direction. Solvation effects have been considered by calculating solvation energies of those closedshell molecules both in ethylene glycol and in water via the MGCM methodology (multigrid continuum model). ${ }^{40,41}$

To study the $\mathrm{Ru}$ doping effects, the system stability was investigated first via a few aspects following the procedures as in 
Scheme 2. Reaction Network of Isomer B Depolymerization and Hydrogenation on the Ni(111) Surface ${ }^{a}$

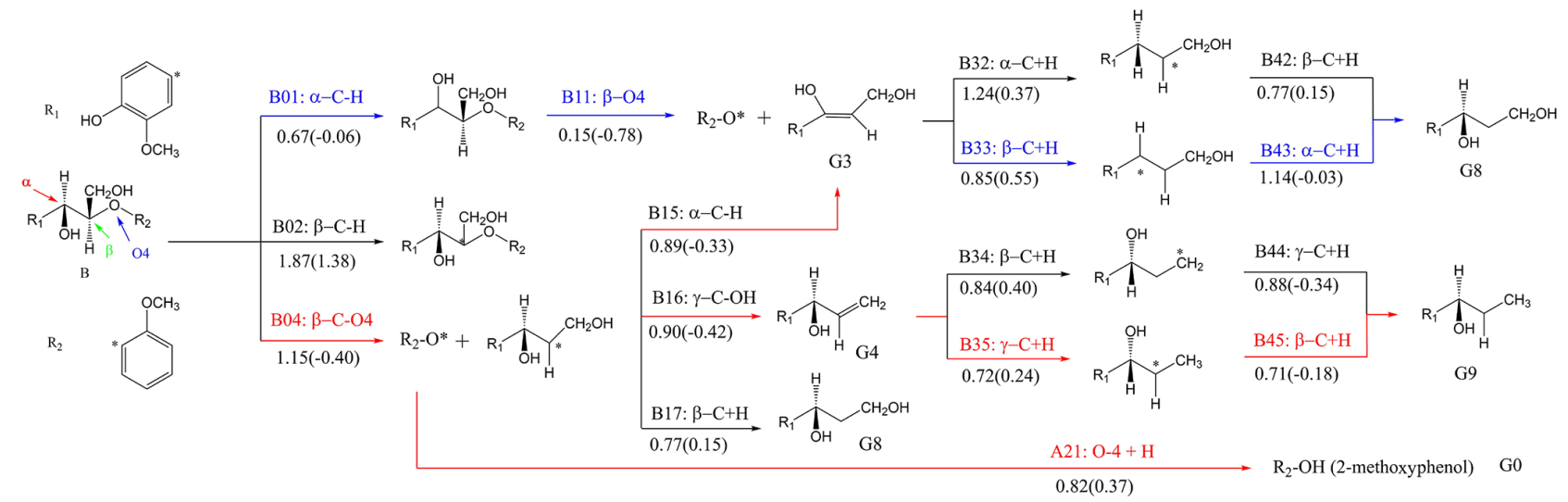

${ }^{a}$ Blue and red pathways are preferred reactions from $\alpha$-C and $\beta$-C sides, respectively.

Table 1. Adsorption Energies ( $E_{\text {ads }}$ in electronvolts) of Closed-Shell Species and Small Molecules on the $\mathrm{Ni}(111), \mathrm{Ru}(0001)$, and $\mathrm{Ru}-\mathrm{Ni}(111)$ Surfaces and Their Solvation Energies in EG $\left(E_{\mathrm{sol}}^{\mathrm{EG}}\right)$ and Water $\left(E_{\mathrm{sol}}^{\mathrm{H}_{2} \mathrm{O}}\right)^{a}$

\begin{tabular}{|c|c|c|c|c|c|c|c|}
\hline species & $\mathrm{Ni}(111)$ & $\mathrm{Ru}(0001)$ & $\mathrm{Ru}-\mathrm{Ni}(111)$ & $E_{\mathrm{sol}}^{\mathrm{EG}}$ & $E_{\mathrm{sol}}^{\mathrm{H}_{2} \mathrm{O}}$ & $N^{\text {covered }}$ & $E_{\mathrm{ads}}(\mathrm{EG})$ \\
\hline A & -2.28 & -3.59 & -2.28 & -0.60 & -1.00 & 20 & -0.21 \\
\hline B & -2.29 & -3.42 & -2.35 & -0.60 & -1.02 & 20 & -0.23 \\
\hline $\mathrm{C}$ & -1.76 & -3.12 & -1.83 & -0.60 & -1.02 & 20 & 0.31 \\
\hline $\mathrm{D}$ & -1.86 & -3.16 & -1.97 & -0.62 & -1.04 & 20 & 0.20 \\
\hline $\mathrm{E}$ & -2.33 & -3.43 & -2.39 & -0.56 & -0.59 & 20 & -0.25 \\
\hline G0 & -1.24 & -1.96 & -1.18 & -0.32 & -0.47 & 12 & -0.04 \\
\hline G1 & -2.34 & -3.38 & -2.58 & -0.49 & -0.75 & 13 & -0.90 \\
\hline G2 & -2.07 & -3.28 & -2.24 & -0.39 & -0.61 & 13 & -0.80 \\
\hline G3 & -1.78 & -3.07 & -2.30 & -0.45 & -0.73 & 13 & -0.33 \\
\hline G4 & -1.96 & -2.99 & -2.23 & -0.36 & -0.73 & 13 & -0.62 \\
\hline G5 & -1.62 & -2.47 & -1.78 & -0.49 & -0.79 & 13 & -0.22 \\
\hline G6 & -1.57 & -2.29 & -1.76 & -0.44 & -0.69 & 13 & -0.26 \\
\hline G7 & -1.44 & -2.30 & -1.58 & -0.35 & -0.60 & 13 & 0.01 \\
\hline G8 & -1.20 & -2.02 & -1.31 & -0.48 & -0.49 & 13 & 0.19 \\
\hline G9 & -1.29 & -1.97 & -1.43 & -0.35 & -0.60 & 13 & 0.01 \\
\hline G10 & -1.53 & -2.17 & -1.53 & -0.26 & -0.26 & 13 & -0.32 \\
\hline
\end{tabular}

${ }^{a} N^{\text {covered }}$ stands for the surface metal atoms covered by the adsorbates. $E_{\text {ads }}(E G)$ is the solvation effect-corrected adsorption energy of a species on the $\mathrm{Ni}(111)$ surface in ethylene glycol.

ref 42 . The solubility was calculated in a bulk model containing $32 \mathrm{Ni}$ atoms. Segregation and near surface energies were obtained via a $p$ - $(2 \times 2)$ slab with six layers, and the top four layers were optimized. The island formation energy was calculated on a $p-(3 \times 3)$ slab with four layers, and the top two layers were relaxed. As listed in Table S5, the energy of dissolving one $\mathrm{Ru}$ atom into the $\mathrm{Ni}$ bulk is $0.53 \mathrm{eV}$, implying the a relative instability in forming the alloy. However, the endothermic energy would be compensated by the entropic contributions as $\mathrm{Ru}$ can replace $\mathrm{Ni}$ atoms from three directions with higher disorder, which corresponds to the higher entropy and therefore reduces the dissolving energy. ${ }^{42,43} \mathrm{~A}$ small exothermic segregation energy $(-0.05 \mathrm{eV})$ implies that penetration of $\mathrm{Ru}$ into the bulk is slightly preferable and can occur both on the surface and in the bulk. From the positive island formation energy $(0.12 \mathrm{eV})$, it is safe to derive that $\mathrm{Ru}$ dispersion on the surface is preferred. According to this analysis, $\mathrm{Ru}$ effects have been investigated by substituting the $\mathrm{Ni}$ atom under the breaking bonds with $\mathrm{Ru}$ on the top layer. In other words, the active site $\mathrm{Ni}$ atoms for a variety of types of bond breakages as well as adsorption structures have been replaced by the $\mathrm{Ru}$ atoms specifically, depending on the reaction types.

All energies presented in the schemes and diagrams were obtained from the gas phase and slab calculations without solvent or zero-point energy contributions except as indicated otherwise. All coordinates of these structure geometries as well as the related transition states in this work are listed in the Supporting Information by using VASP POSCAR's format. In addition, the data are also freely accessible from the ioChem$\mathrm{BD}$ database, ${ }^{44,45}$ and the instructions to use this platform have also been described in the Supporting Information.

\section{RESULTS AND DISCUSSION}

3.1. Adsorption. Adsorption energies of reactants (A-D) and products (G0-G10 in Schemes 1 and 2) on $\mathrm{Ni}(111)$, $\mathrm{Ru}(0001)$, and $\mathrm{Ru}$-doped $\mathrm{Ni}(111)$ surfaces and their solvation energies in water and EG are listed in Table 1. Adsorption geometries of these four lignin $\beta$-O-4 models are shown in Figure 2. Isomers $\mathrm{A}$ and $\mathrm{B}$ with $\beta$-S carbons bind to the surface at least $0.40 \mathrm{eV}$ stronger than $\beta-\mathrm{R}$ configurations do (C and D), because of the chirality difference at $\beta$-C caused by changing 
the relative positions of the $\mathrm{H}$ and $\mathrm{CH}_{2} \mathrm{OH}$ groups. On the contrary, the chirality at $\alpha$-C has little effect on the adsorption energies. For instance, isomers $\mathrm{A}$ and $\mathrm{B}$ adsorb to the surface with similar exothermic energies of -2.28 and $-2.29 \mathrm{eV}$, respectively, on $\mathrm{Ni}(111)$.

To ensure the stabilities of $\mathrm{A}$ and $\mathrm{B}$ isomers, we also tried two geometries derived from the $\mathrm{A}$ isomer by rotating the $\mathrm{C}_{\alpha}-$ $\mathrm{C}_{\beta}$ bond and using the other face to adsorb, see Figure 2. For these alternative structures, the molecule adsorbs on the surface with only one aromatic unit connecting to the $\beta$-O-4 bond, leaving the other aromatic unit intact. When $\mathrm{A}$ adsorbs to the surface by using the other face, the aryl-surface interactions are blocked for both sides by the $\gamma-\mathrm{CH}_{2} \mathrm{OH}$ group and A adsorbs on the surface in a tilted way. As the aryl-surface interactions make the main contributions to the adsorption energy, these two geometries with only one aryl-surface interaction and without any aryl-surface interactions have small adsorption energies of -1.08 and $-0.69 \mathrm{eV}$, respectively, showing the stereoeffects in the adsorption energies.

There are two important aspects to consider about the adsorption of very large molecules from the liquid phase. For molecules like the lignin A model, a sergeant-and-soldier principle can be applied to understand adsorption. ${ }^{46}$ The largest driving force is the adsorption of the aryl groups that act as directing groups for adsorption; this fact coupled to the rigidity of the $\mathrm{Ar}-\mathrm{C}_{\alpha}-\mathrm{C}_{\beta}-\mathrm{O}_{4}-\mathrm{Ar}$ structure implies that $\mathrm{C}_{\beta}$ stands relatively far from the surface, and this will prevent an easy activation. This can be seen from the fact that molecular adsorption for the configurations with two rings on the surface is double that of only one ring interacting with the catalyst. In addition, the large adsorption energy arising from the large molecule sizes of the $\beta$-O- 4 model would also lead to a large energy span in the reaction profile. However, adsorption occupies a large number of sites, and thus, the adsorption energy per area is more meaningful for assessing the real strength of the binding at the interface. For instance, hydrogen has been reported to affect co-adsorption; ${ }^{47}$ however, in our case, the reactions are performed in solvent (EG), and thus, a competition among hydrogen, solvent, and lignin for the active sites will appear. The corresponding adsorptions are $-0.60 \mathrm{eV} /$ $\mathrm{H}$ atom, $-0.71 \mathrm{eV}$ for $\mathrm{EG}$, and around $-2.28 \mathrm{eV}$ for $\mathrm{A}$, but the corresponding adsorption energy densities (divided by the number of metal atoms in the ensembles, $N^{\text {covered }}$ in Table 1 ) are quite similar. In addition, the reactions are performed in solvent. Solvent contributions are difficult to assess ${ }^{48}$ and would require extensive first-principles molecular dynamics sampling, ${ }^{49}$ which are not possible for the lignin dimers presented here. Instead, we have followed two methods to report the contributions: (i) adsorption/desorption events calculated in the gas phase (rendering large values, around $2 \mathrm{eV}$ for the model A lignin) and (ii) introduction of the replacement energy that implies removal of some solvent from the surface and desolvation of the reactants from our continuum model (see the Born-Haber cycle in section S3.2). The discussion in terms of only the competition between the solvent and lignin model A is sufficient to identify potential bottlenecks.

On the $\mathrm{Ru}(0001)$ surface, our results show that adsorptions for all species are much stronger than those on $\mathrm{Ni}(111)$. Therefore, the adsorption of intermediate species on a $\mathrm{Ru}-$ decorated $\mathrm{Ni}(111)$ surface would be between those on pure $\mathrm{Ni}(111)$ and $\mathrm{Ru}(0001)$ surfaces. This has been confirmed by the calculated adsorption energies on the $\mathrm{Ru}-\mathrm{Ni}(111)$ surface. When $\mathrm{A}$ and $\mathrm{B}$ approach the $\mathrm{Ru}-\mathrm{Ni}(111)$ surface, the adsorption energies depend on their motifs above the $\mathrm{Ru}$ atom. Two A structures with an aromatic part and $\mathrm{O}$ (from $\beta$ $\mathrm{O}-4$ ) above the $\mathrm{Ru}$ atom, denoted as $\mathrm{Ar}_{\mathrm{Ru}}$ and $\mathrm{O}_{\mathrm{Ru}}$ respectively, were optimized, and their adsorption energies are -2.28 and $-2.13 \mathrm{eV}$, respectively. The local surface environment and lignin rigidity would account for the weaker $\mathrm{O}_{\mathrm{Ru}}$ adsorptions. The Ni atoms surrounding $\mathrm{Ru}$ have been increased by $0.02 \AA$, and $\mathrm{Ru}$ is $0.06 \AA$ above the surface. The local surface roughness pushes the adsorbate up in the $z$ direction slightly, compared to the flat $\mathrm{Ni}(111)$ surface. For example, the carbon atoms from the benzene ring connecting the $\mathrm{O}$ atom shift upward slightly with a range from 0.003 to $0.098 \AA$, weakening the aryl-metal interaction. In addition, the aryl far from the $\mathrm{O}$ atom nearly keeps its structure unaltered, and this rigidity might bring out the intramolecule strain, further reducing its adsorption strength.

3.2. Reaction Network. Because of their lower adsorption energies, $C$ and $D$ were not further considered in the depolymerization and hydrogenation network. For A and B conversions on the $\mathrm{Ni}(111)$ surface, as reported experimental results show that aromatic parts are undisturbed during the catalytic process by using an activated carbon-supported $\mathrm{Ni}$ $(\mathrm{Ni} / \mathrm{AC})$ catalyst, ${ }^{17}$ only reactions related to $\alpha$ - and $\beta$-C were considered, and the full decomposition pathways are outlined in Schemes 1 and 2 and Figure S3 and S4. Two C-C bonds, $\mathrm{C}_{\alpha}-\mathrm{C}_{\text {aromatic }}$ and $\mathrm{C}_{\alpha}-\mathrm{C}_{\beta}$, were assumed to require high barriers to proceed because of interactions lacking between these bonds and the surface metals. The reactants can be treated as EG with its $\mathrm{H}$ atoms being replaced by aromatic moieties and $\mathrm{CH}_{2} \mathrm{OH}$; a previous study of EG dehydrogenation shows that the $\mathrm{C}-\mathrm{C}$ bond breaks in the late reaction steps. ${ }^{50}$ In addition, in the previous experimental studies over the Ni catalyst, ${ }^{17} \mathrm{C}_{\text {aromatic }}-$ $\mathrm{O}, \mathrm{C}_{\alpha}-\mathrm{C}_{\text {aromatic }}$ and $\mathrm{C}_{\alpha}-\mathrm{C}_{\beta}$ bond scissions were not observed and the $\mathrm{C}_{\beta}-\mathrm{C}_{\gamma}$ bond breaking product accounts for only $1 \%$ of the product distribution. Therefore, aromatic hydrogenation and $\mathrm{C}_{\text {aromatic }}-\mathrm{O}$ and $\mathrm{C}-\mathrm{C}$ bond breaking are not further considered. Calculated reaction barriers and energies from $\mathrm{A}$ and B isomers are also shown in Schemes 1 and 2, and the energy diagrams and geometries are plotted in Figures 3 and 4. To describe the complex reaction network more clearly, all

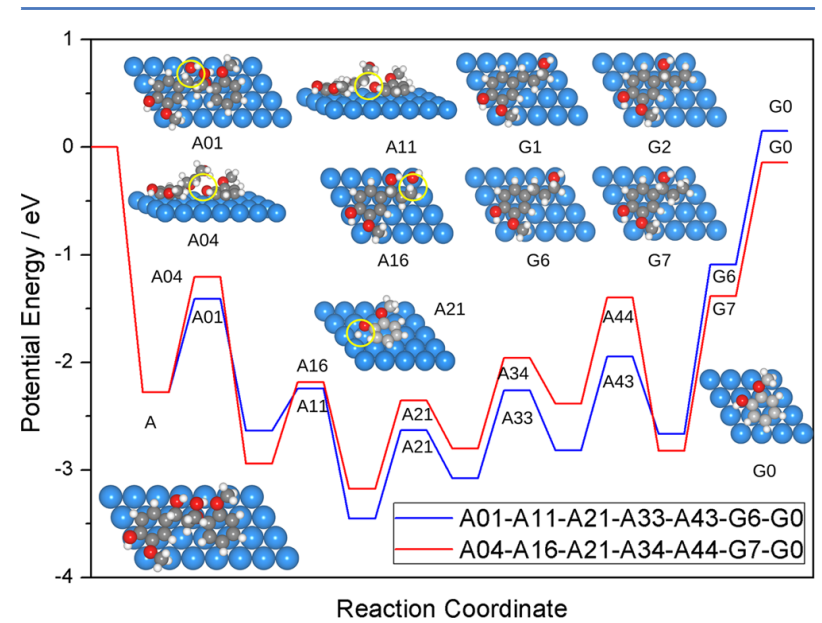

Figure 3. Reaction profile and intermediates' structures of isomer A conversion on the $\mathrm{Ni}(111)$ surface. For smaller molecules on a $p-(7 \times$ 4) $\mathrm{Ni}(111)$ surface, some of the surface metal atoms are not shown in the figures. Same color code as in Figure 2. 


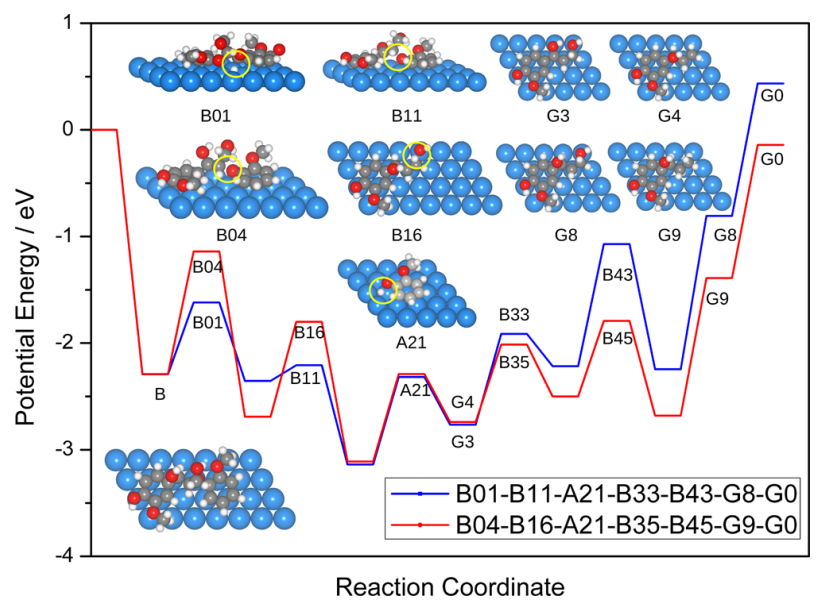

Figure 4. Reaction profile and intermediate structures of isomer B conversion on the $\mathrm{Ni}(111)$ surface. Same color code as Figure 2.

steps in the schemes are labeled with notations such as A01, A11, etc. Here, A01 stands for the first possible elementary reaction in the first reaction stage from the $A$ isomer. Because of the different chirality of $\mathrm{A}$ and $\mathrm{B}$ isomers, the reactions that take place at the same $\alpha$ - or $\beta$-C positions at the same stage in two isomer conversions are labeled with the same number even though the bond breaking types are different. For instance, A01 and $\mathrm{B} 01$ are $\mathrm{C}-\mathrm{OH}$ and $\mathrm{C}-\mathrm{H}$ bond breakings, respectively. $\mathrm{C}-\mathrm{OH}$ from the $\mathrm{B}$ isomer is not labeled as $\mathrm{B} 01$ because this bond is not activated in the adsorbed $\mathrm{B}$ isomer.

3.2.1. Reactions Starting from Isomer $A$. The reaction network and the energy profile starting from isomer A are shown in Scheme 1 and Figure 3. For reactions from the $\alpha$-C side of this isomer, there are two competing reactions, $\mathrm{C}-\mathrm{OH}$ (A01) and $\mathrm{O}-\mathrm{H}(\mathrm{A03})$ bond ruptures. The barriers (reaction energies) for them are $0.87(-0.36)$ and $1.00(0.38) \mathrm{eV}$, respectively. After the A03 step, $\alpha-\mathrm{C}-\mathrm{O}$ breaking (A12) proceeds with lowest barriers of $0.38 \mathrm{eV}$ in three possible steps (A12-A14), and this step is highly exothermic with an energy of $-1.04 \mathrm{eV}$. As a result, a common intermediate appears from the A01 step or the combined A03 and A12 steps. Then, it is interesting to find that the $\beta$-O-4 bond is very easy to break (A11) both kinetically and thermodynamically with energies of $0.39(-0.82) \mathrm{eV}$. Such a lower barrier for $\beta$-O-4 bond rupture is attributed to the formation of a highly conjugated coniferyl alcohol (G1). After A01, another $\alpha$-C hydrogenation step (A22) to produce $\mathrm{E}$ has been calculated, and this step has an activation barrier of $0.85 \mathrm{eV}$ and is nearly thermoneutral by $0.06 \mathrm{eV}$. The inverse reaction of A01 is difficult because of its higher barrier of $1.23 \mathrm{eV}$. Hence, once the $\mathrm{C}-\mathrm{OH}$ bond breaks, both the hydrogenation step (A22) and the reverse reaction of A01 cannot compete with $\beta$-O-4 bond breakings. Another product of the $\beta$-O-4 bond cleavage is 2 -methoxy-phenolate, which requires $0.82 \mathrm{eV}$ (A21) to be hydrogenated into 2methoxy-phenol (G0). The desorption energies for G0 and G1 are 1.24 and $2.34 \mathrm{eV}$, respectively. When solvation effects are considered, their desorption energies decrease to 0.04 and 0.90 $\mathrm{eV}$, respectively, in the EG solvent. Compared to the higher barrier to desorb for G1, two hydrogenation steps at the $\mathrm{C}=\mathrm{C}$ bond (A33 and A43) would take place, and the hydrogenation product is G6. In the last step, G6 would desorb in the gas phase (EG solvent) with a lower barrier of $1.57(0.26) \mathrm{eV}$.
For reactions starting from the $\beta-\mathrm{C}$ side, $\beta-\mathrm{C}-\mathrm{H}(\mathrm{A} 02)$ and direct $\beta$-O-4 bond breaking (A04), were first investigated. Our results show that the A02 step is blocked by its high barrier and endothermic energy of 1.92 and $1.49 \mathrm{eV}$, respectively, because of the rigidity of the lignin structure arising from the strong interactions between two aromatic units that prevents the rotation of the $\mathrm{C}_{\alpha}-\mathrm{C}_{\beta}$ bond. Hence, the possible reactions after the $\beta-\mathrm{C}-\mathrm{H}$ step have not been considered in the next step. For direct $\beta$-O-4 bond breaking (A04), this step needs a relatively low barrier of $1.07 \mathrm{eV}$ and is exothermic by $-0.66 \mathrm{eV}$. Therefore, this step would compete with the $\mathrm{C}-\mathrm{OH}$ and $\mathrm{O}-\mathrm{H}$ bond breakings from the $\alpha$-C side. One of its products, 2methoxy-phenolate, would be hydrogenated to G0 and then desorb. For the other product, there are three possible reactions that can proceed; one is the direct hydrogenation step (A17) that takes place with a comparable energy of $0.82(-0.05) \mathrm{eV}$, while its product G5 requires $1.62(0.22) \mathrm{eV}$ to desorb in the gas phase (or EG solvent). The other two are $\mathrm{C}-\mathrm{OH}$ bond breakings from $\alpha$-C (A15) and $\beta$-C (A16) sides with energies of $0.86(-0.45)$ and $0.76(-0.23) \mathrm{eV}$, respectively. Among them, step A16 with the lowest barrier is the most kinetically favorable. The A15 step produces the coniferyl alcohol (G1), and the Al6 step produces another unsaturated intermediate (G2) that needs a high energy of $2.07(0.80) \mathrm{eV}$ to desorb in the gas phase (or EG solvent). From G2, two hydrogenation steps proceed on the $\beta$-C (A34) and $\gamma$-C (A44) sides and the product G7 needs $1.44(0.01) \mathrm{eV}$ to desorb.

For the analysis presented above, we noticed that $\mathrm{C}-\mathrm{OH}$ and $\beta$-O- 4 scissions can affect each other when they proceed in a different sequence order. For example, $\mathrm{C}-\mathrm{OH}$ bond breaking in A01 facilitates the subsequent $\beta-\mathrm{O}-4$ bond rupture (A11) by forming the conjugated structures. On the other hand, direct $\beta$ $\mathrm{O}-4$ bond cleavage (A04) facilitates $\mathrm{C}-\mathrm{OH}$ bond ruptures (A15 and A16) by $\sim 0.10 \mathrm{eV}$, compared with the A01 step.

3.2.2. Reactions Starting from Isomer B. The B isomer can be regarded as the product of changing the $\mathrm{H}$ and $\mathrm{OH}$ group positions (epimers) at $\alpha$-C in the $\mathrm{A}$ isomer, and the reaction network and profile for its conversion are outlined in Scheme 2 and Figure 4. For reactions starting at the $\alpha$-C side, only the $\mathrm{C}-\mathrm{H}$ bond interacts with the surface; thus, the $\alpha-\mathrm{C}-\mathrm{H}$ bond breaking proceeds first with a barrier of $0.67 \mathrm{eV}$, and this step is almost thermodynamically neutral, $-0.06 \mathrm{eV}$. Then, $\beta$-O-4 bond scission (B11) is greatly promoted with energies of 0.15 $(-0.78) \mathrm{eV}$. This indicates that conjugation again plays a significant role in reducing the barrier to breaking the $\beta$-O-4 bond. In addition, the barrier in $\mathrm{B} 11$ is $0.24 \mathrm{eV}$ lower than that in the A11 step $(0.39 \mathrm{eV})$. The differences between initial structures of $\mathrm{A} 11$ and $\mathrm{B} 11$ are the $\mathrm{H}$ and $\mathrm{OH}$ groups at the $\alpha$-C side. As oxygen has a higher electron affinity, more electrons would be transferred from the $\beta$-O-4 bond to the $\alpha-\mathrm{C}-\mathrm{OH}$ bond and the $\beta-\mathrm{O}-4$ bond in $\mathrm{B} 11$ is more activated than that in A11, resulting in a lower barrier. 2-Methoxy-phenolate and G3 are the products in this step. From G3, two sequential C hydrogenation steps (B33 and B43) proceed with barriers of $0.85(0.55)$ and $1.14(-0.03) \mathrm{eV}$, respectively, and G8 is the product that needs less energy $(1.20 \mathrm{eV})$ to desorb. The solvent-corrected adsorption energy of G8 is $0.19 \mathrm{eV}$; this means that it will desorb once it is formed.

For reactions from the $\beta$-C side, similar to those from $\mathrm{A}, \beta$ $\mathrm{C}-\mathrm{H}$ bond rupture (B02) again requires the highest barrier among all reactions, showing that the change in chirality from that of $\alpha$-C has little effect on reducing the structure's rigidity. Thus, reactions after the B02 step are no longer considered. For 
direct $\beta$-O- 4 bond breaking (B04), the activation barrier (1.15 $\mathrm{eV})$ is $0.08 \mathrm{eV}$ higher than that in the A04 step. One product is 2-methoxy-phenolate, and the other one would undergo three possible reactions, $\alpha-\mathrm{C}-\mathrm{H}(\mathrm{B} 15)$ and $\gamma-\mathrm{C}-\mathrm{OH}$ bond breakings (B16) and $\beta$-C hydrogenation (B17), the products being G3, G4, and G8, respectively. The energies in the B15-B17 steps are $0.89(-0.33), 0.90(-0.42)$, and $0.77(0.15) \mathrm{eV}$, respectively. From G3, two hydrogenation steps would proceed, and the final product is G8 as stated before. From G4, both $\beta$-C (B34) and $\gamma$-C (B35) hydrogenations take place with energies of $0.84(0.40)$ and $0.72(0.24) \mathrm{eV}$, respectively. In the next steps, the energies are $0.88(-0.34)$ and $0.71(-0.18)$ $\mathrm{eV}$ for the B44 and B45 steps, respectively. The hydrogenation product G9 needs $1.29(0.01) \mathrm{eV}$ to desorb in the gas phase (or EG solvent). Considering the energies in the three initial steps (B01-B03), it is safe to infer that the reaction proceeds via $\alpha$ $\mathrm{C}-\mathrm{H}$ scission first, followed by the $\beta$-O-4 bond cleavage and hydrogenation steps. The products should be G0 and G8.

3.2.3. Comparison of the Reactivity for $A$ and $B$ Isomers. As described above, the most preferred reaction pathways from $\mathrm{A}$ and $\mathrm{B}$ isomers on the $\mathrm{Ni}(111)$ surface have been selected and the energy diagrams are shown in Figure 5. G0, G6, G7, etc., in

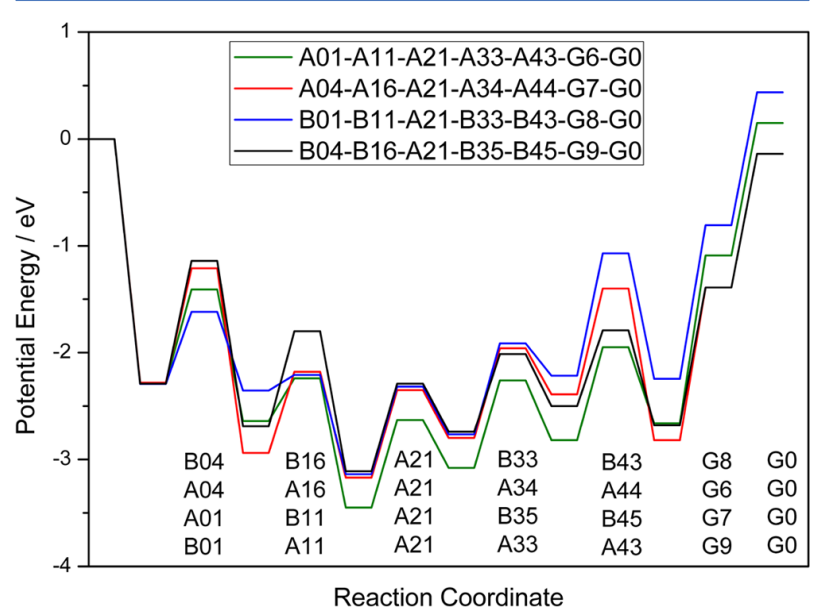

Figure 5. Comparison between the reaction energy profiles for A and $\mathrm{B}$ conversions on the $\mathrm{Ni}(111)$ surface.

the profiles stand for their desorption steps. For isomer A, the pathway starting from the $\alpha$-C side is A01-A11-A21-A33A43-G6-G0, with sequential reaction barriers of $0.87,0.39$, $0.82,0.82,0.87,1.57$, and $1.24 \mathrm{eV}$. Similarly, for the other path starting from the $\beta$-C side, the sequential barriers (A04-A16A21-A34-A44-G7-G0) are 1.07, 0.76, 0.82, 0.84, 0.99, 1.44, and $1.24 \mathrm{eV}$. In the last two steps, product desorptions require more energy. However, when solvation effects are considered, the desorption barriers are diminished. For instance, in the EG solvent, the barriers of G6 and G7 desorptions decrease from 1.57 and $1.44 \mathrm{eV}$ to 0.24 and $0.20 \mathrm{eV}$, respectively. For the B isomer, the barriers in the pathway starting from the $\alpha$-C side (B01-B11-A21-B33-B43-G8-G0) are 0.67, 0.15, 0.82, $0.85,1.14,1.20$, and $1.24 \mathrm{eV}$, respectively. The barriers in the pathway starting from the $\beta$-C side (B04-B16-A21-B35B45-G9-G0) are 1.15, 0.90, 0.82, 0.72, 0.71, 1.29, and 1.24 $\mathrm{eV}$. Thus, the reactions starting from the $\alpha-\mathrm{C}$ side are kinetically preferred. For elementary reactions in two pathways staring from the $\alpha$-C side for A and B isomers, entropy and zero-point energy corrections to their activation barriers have been considered by analyzing the vibration modes under $473 \mathrm{~K}$, which is the experiment temperature from ref 17 . As shown in Table S7, entropy contributions are very small for the surface reactions, and this has also been shown in previous studies by Hamou et al. ${ }^{22}$ For reactions related to the A isomer, A01, A33, and B43 have very close barriers, and it is difficult to tell which one is the rate-limiting step. However, for reactions related to the $\mathrm{B}$ isomer, $\mathrm{B} 43$ has the highest barrier of $1.03 \mathrm{eV}$. This again implies the chirality effects in the reaction pathways.

3.2.4. Reactions on the Ru-Doped Ni(111) Surface. A previous experimental study by Yan et al. ${ }^{18}$ demonstrated that bimetallic $\mathrm{Ru}-\mathrm{Ni}$ exhibits superior activity during the hydrogenolysis of lignin in water. By combination of XPS and X-ray absorption spectroscopy methods, it was found that the catalyst is surfaced-enriched with $\mathrm{Ni}$. In the study presented here, the $\mathrm{Ru}$ effects were studied via a simple model by replacing one surface $\mathrm{Ni}$ with a $\mathrm{Ru}$ atom (impurity model), and then the adsorption properties and transition states were optimized. Reaction barriers and energies on $\mathrm{Ni}(111)$ and $\mathrm{Ru}-\mathrm{Ni}(111)$ surfaces are listed in Table 2, and effects of $\mathrm{Ru}$ on the energy profiles for the selected pathways are plotted in Figure S8.

Table 2. Comparison of Activation Barriers, $E_{\mathrm{a}}$, and Reaction Energies, $\Delta E$ (both in electronvolts), on Pure $\mathrm{Ni}(111)$ and Ru-Doped Ni(111) Surfaces

\begin{tabular}{|c|c|c|c|c|c|}
\hline \multirow[b]{2}{*}{ label } & \multirow[b]{2}{*}{ type } & \multicolumn{2}{|c|}{$\mathrm{Ni}(111)$} & \multicolumn{2}{|c|}{$\mathrm{Ru}-\mathrm{Ni}(111)$} \\
\hline & & $\overline{E_{\mathrm{a}}}$ & $\overline{\Delta E}$ & $E_{\mathrm{a}}$ & $\overline{\Delta E}$ \\
\hline A01 & $\alpha-\mathrm{C}-\mathrm{OH}$ & 0.87 & -0.36 & 0.78 & -0.12 \\
\hline A04 & $\beta-\mathrm{O}-4$ & 1.07 & -0.66 & 0.77 & -0.39 \\
\hline A11 & $\beta-\mathrm{O}-4$ & 0.39 & -0.82 & 0.29 & -1.20 \\
\hline A15 & $\alpha-\mathrm{C}-\mathrm{OH}$ & 0.86 & -0.45 & 1.01 & -0.39 \\
\hline A16 & $\beta-\mathrm{C}-\mathrm{OH}$ & 0.76 & -0.23 & 0.72 & -0.04 \\
\hline $\mathrm{A} 21$ & $\mathrm{O} 4+\mathrm{H}$ & 0.82 & 0.37 & 1.06 & 0.74 \\
\hline B01 & $\alpha-\mathrm{C}-\mathrm{H}$ & 0.67 & -0.06 & 0.74 & -0.09 \\
\hline B04 & $\beta-\mathrm{O}-4$ & 1.15 & -0.40 & 0.96 & -0.18 \\
\hline B11 & $\beta-\mathrm{O}-4$ & 0.15 & -0.78 & 0.05 & -1.18 \\
\hline B15 & $\alpha-\mathrm{C}-\mathrm{H}$ & 0.89 & -0.33 & 0.56 & -0.68 \\
\hline B16 & $\gamma-\mathrm{C}-\mathrm{OH}$ & 0.90 & -0.42 & 0.87 & -0.20 \\
\hline
\end{tabular}

When $\alpha-\mathrm{C}-\mathrm{OH}$ bond cleaves (A01) over the substituted $\mathrm{Ru}$ atom, the barrier decreases slightly by $0.09 \mathrm{eV}$, and the process is less exothermic by $0.24 \mathrm{eV}$. Large differences are observed in direct $\beta$-O-4 bond scission (A04) with the barrier decreasing from 1.07 to $0.77 \mathrm{eV}$, and the reaction is less exothermic by $0.28 \mathrm{eV}$. Ru has little effect on the barrier of $\beta-\mathrm{O}-4$ in the second step (A11) but a strong effect on the reaction energy (from -0.82 to $-1.20 \mathrm{eV}$ ). The $\alpha-\mathrm{C}-\mathrm{OH}$ breaking step (A15) after $\mathrm{A} 04$ needs $0.15 \mathrm{eV}$ more energy to proceed on the $\mathrm{Ru}-$ $\mathrm{Ni}(111)$ surface, and the reaction energy decreases slightly by $0.06 \mathrm{eV}$. The barrier of another $\alpha-\mathrm{C}-\mathrm{OH}$ scission step (A16) changes slightly by $0.04 \mathrm{eV}$, and the process turns out to be thermoneutral. Furthermore, for hydrogenation of 2-methoxyphenolate to G0 (A21), Ru also increases the barrier by $0.24 \mathrm{eV}$ and the reaction becomes more endothermic from 0.37 to 0.74 $\mathrm{eV}$.

For the reactions of $\mathrm{B}, \mathrm{Ru}$ also decreases the barrier by 0.16 $\mathrm{eV}$ for direct $\beta-\mathrm{O}-4$ bond scission (B01). A larger release of energy from the second $\beta$-O-4 bond (B04) has been observed again, in agreement with reaction from $\mathrm{A}$. It is interesting to observe that for $\mathrm{B} 15$, the $\mathrm{C}-\mathrm{H}$ bond breaking after the $\mathrm{B} 04$ step is also activated by $0.33 \mathrm{eV}$ and is thermodynamically more favorable by $-0.68 \mathrm{eV}$. However, A15 becomes more difficult 
to reach as the energy requirement increases by $0.15 \mathrm{eV}$ on the $\mathrm{Ru}-\mathrm{Ni}(111)$ surface. Compared to those of A01 and A15, the lower barrier in the first $\mathrm{C}-\mathrm{H}$ breaking step (B01) due to its chirality at $\alpha$-C and the barrier lowered by the doped $\mathrm{Ru}$ in the second step (B15) demonstrate the synergistic effects of stereocenters and $\mathrm{Ru}$ on the promotion of lignin conversion. For the $\mathrm{C}-\mathrm{OH}$ bond in $\mathrm{B} 16$, the barrier is slightly reduced from 0.90 to $0.87 \mathrm{eV}$ and the reaction is less exothermic by 0.23 $\mathrm{eV}$, which is similar to the A situation. Thus, for $\mathrm{C}-\mathrm{OH}$ bond breaking, Ru has weak (for A16 and B16) or negative (for A15) effects on the reaction barriers and reactions become more endothermic by $0.20-0.30 \mathrm{eV}$. For $\beta-\mathrm{O}-4$ bond breaking in the first steps (A04 and B04), doped Ru facilitates the reaction by reducing the barrier by $\leq 0.30 \mathrm{eV}$, with reactions becoming less exothermic by $0.20 \mathrm{eV}$. For $\beta$-O-4 bond breaking in the second steps (A11 and B11), Ru has little effect on the barriers but the reaction becomes more exothermic by $0.40 \mathrm{eV}$. In the final step, the introduced $\mathrm{Ru}$ increases the barrier and energy for phenolate hydrogenation into phenol by 0.27 and $0.35 \mathrm{eV}$, respectively. This can be attributed to the $\mathrm{O}$ affinity of $\mathrm{Ru}$ being stronger than that of $\mathrm{Ni}$, which stabilizes the phenolate species. In spite of that, this step can be promoted by the high surface $\mathrm{H}$ concentration and $\mathrm{H}_{2} \mathrm{O}$ via the formation of hydrogen bonds.

3.3. Discussion. 3.3.1. Chirality, Rigidity, and Conjugation Effects. As stated above, three stereoeffects were found in this study: rigidity, chirality, and conjugation. First, the most stable adsorption geometries would be affected by the rigidity of the dimer molecules. For example, when the $\mathrm{H}$ and $\mathrm{CH}_{2} \mathrm{OH}$ group positions are switched at the $\beta$-C side in $\mathrm{A}$ and $\mathrm{B}$ isomers, the products would bind to the surface more weakly by $\sim 0.50 \mathrm{eV}$ (see Table 1). In addition, when the $\mathrm{C}_{\alpha}-\mathrm{C}_{\beta}$ bond rotates, because of the increased strain in the structures, the adsorption energy decreases significantly (Figure 2). To further clarify the effects of rigidity on the adsorption energies, the aromatic units connecting to $\alpha$-C were replaced by $\mathrm{H}$ atoms from $\mathrm{A}$ and $\mathrm{D}$ isomers to eliminate the rigidity (see Figure 6).
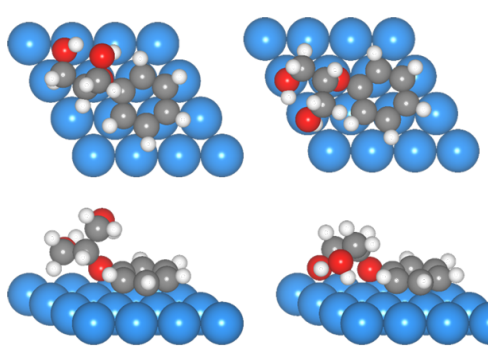

simplified-A: $-1.42 \mathrm{eV}$

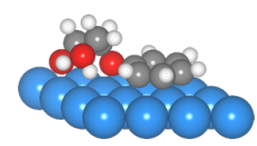

simplified-D: $-1.58 \mathrm{eV}$

Figure 6. Adsorption of rigidity-eliminated isomers from $\mathrm{A}$ and $\mathrm{D}$ by substitution of the aromatic units bound to $\alpha-\mathrm{C}$ with $\mathrm{H}$ atoms on the $\mathrm{Ni}(111)$ surface.

Calculated adsorption energies are -1.42 and $-1.58 \mathrm{eV}$, respectively. It should be emphasized here that the adsorption energies of $\mathrm{A}$ and $\mathrm{D}$ on the $\mathrm{Ni}(111)$ surface are -2.28 and $-1.86 \mathrm{eV}$, respectively. Thus, the replaced $\mathrm{D}$ isomer becomes more stable upon removal of the structural rigidity. The rigidity also has an impact on the reactions from $\alpha$ - and $\beta$-C sides. A previous study that used 2-phenoxyethanol as a surrogate ${ }^{22}$ showed that the $\alpha-\mathrm{C}-\mathrm{H}$ and $\beta-\mathrm{C}-\mathrm{H}$ bond breakings have barriers of 1.21 and $1.14 \mathrm{eV}$, respectively, on $\mathrm{Pt}(111)$. However, these very similar barriers were not observed in the A and B structures on the $\mathrm{Ni}(111)$ surface. In fact, the rigidity inhibits the $\beta-\mathrm{C}-\mathrm{H}$ bond breakings as the $\mathrm{A} 02$ and $\mathrm{B} 02$ steps need to overcome extremely large barriers of 1.92 and $1.87 \mathrm{eV}$, respectively. The $\alpha-\mathrm{C}-\mathrm{H}$ bond breaking barrier in the B01 step is only $0.67 \mathrm{eV}$. As there are two faces of the isomers, we also tried to put the other face of the A isomer on the surface. However, because of the stereoeffects from the $\gamma$-C side, the interactions between aromatic rings and the surface are blocked, which results in the rather weak adsorption.

Second, for chirality effects, the differences from the $\alpha$-C side on the adsorption energies are small, -2.25 and $-2.27 \mathrm{eV}$ for $\mathrm{A}$ and $\mathrm{B}$, respectively. However, this is not the case for the reaction networks. From the reaction network discussed before, the reactions starting from $\alpha$-C and $\beta$-C sides proceed differently for both $\mathrm{A}$ and $\mathrm{B}$ isomers, and the pathway starting at $\alpha-\mathrm{C}$ is more preferable than those from the $\beta$-C side. As shown in the two reaction schemes, changing the chirality at the $\alpha$-C side (from A to B) would also lead to different product distributions. For example, $\mathrm{C}-\mathrm{OH}$ bond scission from the $\alpha$-C side in the $\mathrm{B}$ isomer is unlikely because the lack of interaction of $\mathrm{C}-\mathrm{OH}$ with the surface leads to the unactivated $\mathrm{C}-\mathrm{OH}$ bond. Thus, the $\mathrm{OH}$ group on the $\alpha$-C side of reactant $\mathrm{B}$ remains during the reaction network. It should be emphasized here that the various products from $\mathrm{A}$ and $\mathrm{B}$ cannot be observed when the simple $\beta-\mathrm{O}-4$ surrogates are used in the study. From the comparison between reaction barriers of the $\mathrm{A} 01$ and $\mathrm{B} 01$ steps, it is clear that $\mathrm{C}-\mathrm{H}$ bond breaking with a barrier of $0.66 \mathrm{eV}$ proceeds easier than $\mathrm{C}-\mathrm{OH}$ bond breaking, which has barrier of $0.86 \mathrm{eV}$. Because of the lower barriers in the first two steps ( $\mathrm{C}-\mathrm{H}$ and $\beta$-O-4 scissions), lignin decomposition from reactant $\mathrm{B}$ would proceed much faster than that from reactant $\mathrm{A}$, demonstrating that stereocenters affect the relative rates.

Third, for both A and B conversions, the formation of conjugation structures would significantly reduce the reaction barriers for $\beta$-O- 4 bond breaking. For example, direct bond breakings in A04 and B04 need barriers of 1.04 and $1.15 \mathrm{eV}$, respectively, and the barriers decreased to 0.39 and $0.11 \mathrm{eV}$ for the A11 and B11 steps, respectively. This is an indication of a useful strategy for breaking the $\beta$-O- 4 bond by breaking one bond on the $\alpha$-C side ahead and allowing the formation of conjugation structures.

3.3.2. Solvation Effects. In the reaction profiles of A and B conversions (Figure 5), a large energy span from the lowest structures to the products exists $(\sim 3.0 \mathrm{eV})$. This is mainly due to the large size of the molecule when the gas phase and pure slab energies are used as reference energies. Under real reaction conditions, reactants and products are surrounded by the solvent molecules and solvation energies will decrease the initial energy level (gas phase and the pure slab surface) on a large scale. On one hand, by using the MGCM method, ${ }^{40}$ the computed solvation energies of $\mathrm{A}$ and $\mathrm{B}$ are $-0.60 \mathrm{eV}$ in EG. This means their adsorption energy would approximately be reduced to -1.65 and $-1.67 \mathrm{eV}$, respectively. On the other hand, the surface is also covered by the solvent molecules; if adsorption were to proceed, the surface solvent species would be pushed back into the solvent. Therefore, the energy to remove surface solvent molecules should be paid by the adsorption energy of these adsorbates. The energy for this whole replacement process can then be written as $E_{\text {ads }}(\mathrm{EG}) .^{41,51}$ For example, for the adsorbed $\mathrm{A}$ isomer and EG on the $\mathrm{Ni}(111)$ surface, they roughly cover 20 and $4.5 \mathrm{Ni}$ atoms, respectively. The monolayer-covered $\mathrm{Ni}(111)$ surface 
was optimized by adding up to eight EG molecules on a $p$ - $(6 \times$ 6) supercell (see Figure S7); 20/4.5 surface EG molecules would be substituted by only one A isomer. Thus, the replacement on the surface in the solvent goes as

$$
\mathrm{A}^{\text {solvated }}+\frac{20}{4.5} \mathrm{EG}^{*} \rightarrow \mathrm{A}^{*}+\frac{20}{4.5} \mathrm{EG}^{\text {solvated }}
$$

where $A^{\text {solvated }}$ and $E G^{\text {solvated }}$ are species in the solvation and $A^{*}$ and EG* are surface-adsorbed species. The adsorption energy in this step can be obtained via a Born-Harber cycle as shown in Figure S6 and its corresponding eq S8. For all the reactants and products, their adsorption energies are reduced to a large degree when solvation effects are employed, and this also decreases the large energy span in the energy profiles. The A01-A11-A21-A33-A43-G6-G0 pathway on $\mathrm{Ni}(111)$ is taken as an example to illustrate solvation effects. As shown in Figure 7, when the solvation energy is corrected, the large energy span when taking the gas phase energies as references is reduced to more representative values.

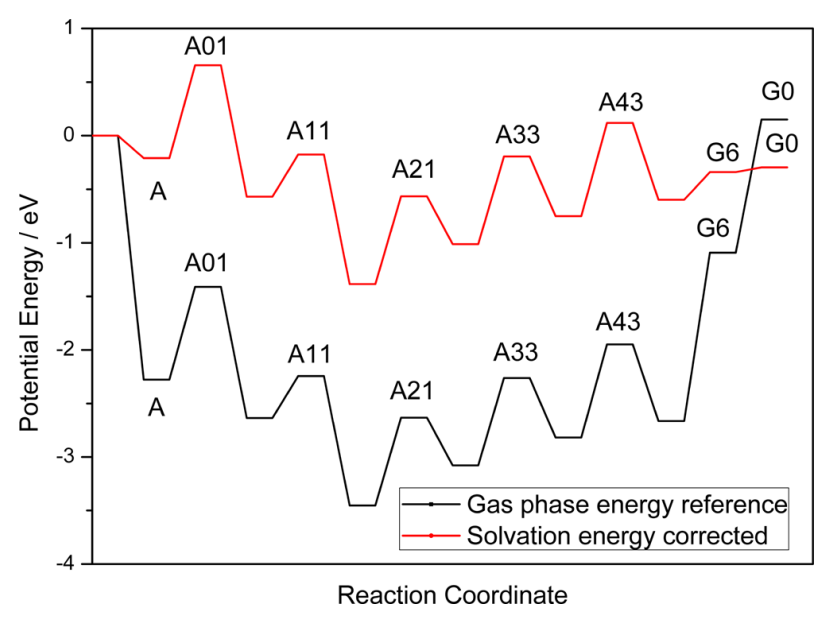

Figure 7. Reaction profiles employing gas phase reference energies and the corrected solvation energy (replacement energy values) for the A01-A11-A21-A33-A43-G6-G0 path on the Ni(111) surface.

3.3.3. Ru Doping Effects. As stated in the adsorption section, on the $\mathrm{Ru}$-doped $\mathrm{Ni}(111)$ surface, $\mathrm{Ar}_{\mathrm{Ru}}$ binds to the surface more strongly $(-2.28 \mathrm{eV})$ than $\mathrm{O}_{\mathrm{Ru}}$ does $(-2.15 \mathrm{eV})$. However, the $\beta$-O- 4 bond breaking barrier of $\mathrm{Ar}_{\mathrm{Ru}}$ is $0.13 \mathrm{eV}$ higher than that of $\mathrm{O}_{\mathrm{Ru}}$. This implies that $\mathrm{Ru}$ participates in lowering the $\mathrm{C}-\mathrm{O}$ bond breaking barriers. To confirm this assumption, the adsorptions of a single $\mathrm{O}$ atom atop $\mathrm{Ni}$ and $\mathrm{Ru}$ atoms in pure $\mathrm{Ni}(111)$ and $\mathrm{Ru}$-doped $\mathrm{Ni}(111)$ surfaces were calculated. The $\mathrm{Ni}-\mathrm{O}$ and $\mathrm{Ru}-\mathrm{O}$ distances are 1.678 and 1.734 $\AA$, respectively, with adsorption energies for the gas phase $\mathrm{O}_{2}$ of -0.54 and $-1.51 \mathrm{eV}$, respectively. The more negative $\mathrm{O}$ adsorption energy atop $\mathrm{Ru}$ indicates that the $\mathrm{Ru}-\mathrm{O}$ bond is much stronger than the $\mathrm{Ni}-\mathrm{O}$ bond. This shows that more electron density is localized between $\mathrm{O}$ and $\mathrm{Ru}$, thus weakening the $\beta-\mathrm{O}-4$ bond when $\mathrm{A}$ and $\mathrm{B}$ adsorb on the surface, in agreement with the earlier transition state $\mathrm{C}-\mathrm{O}$ bond length of $2.103 \AA$ on $\mathrm{Ru}-\mathrm{Ni}(111)$, compared with the longer bond distance of $2.242 \AA$ on $\mathrm{Ni}(111)$. Stronger $\mathrm{Ru}-\mathrm{O}$ interaction can also be implied via comparison of the $\mathrm{O}$ adsorption energies on $\mathrm{Ru}(0001)$ and $\mathrm{Ni}(111)(-2.98$ versus $-2.45 \mathrm{eV})$. Therefore, the doped $\mathrm{Ru}$ strengthens the metal-O bond, which in return weakens the $\beta$-O-4 linkage and promotes $\mathrm{C}-\mathrm{O}$ bond cleavage.

In addition, adsorption energies are more exothermic on $\mathrm{Ru}(0001)$ than on the $\mathrm{Ni}(111)$ surface (Table 1). Thus, employing too much $\mathrm{Ru}$ on the surface would lead to surface poisoning by impeding the refreshing of the catalyst surface during the desorption step of the catalytic cycle. In addition, it has to be emphasized that $\mathrm{Ru}$ also has a strong ability to hydrogenate arenes. ${ }^{52}$ Therefore, a small percentage of $\mathrm{Ru}$ doped into the Ni catalyst would improve the catalytic process. The structure of this active site then recalls single atom catalysts.Our results are in excellent agreement with the experimental observations of Yan et al., ${ }^{18}$ who found a volcano-like behavior exists upon variation of the $\mathrm{Ru}$ percentages in the Ni-based catalyst.

\section{CONCLUSIONS}

In this study, DFT calculations of complex lignin dimer $\beta$-O-4 bond models over $\mathrm{Ni}(111)$ and $\mathrm{Ru}$-doped surfaces were performed. The reaction network accompanied by the stereoeffects and $\mathrm{Ru}$ doping effects has been investigated. Our results show that stereocenters have three effects: on the adsorption structures, on the reaction pathways in the network, and on product distributions. The chirality at the $\beta$-C side and the rigidity are important factors for the different adsorption energies of four reactant candidates and for the reactions from both $\alpha$-C and $\beta$-C sides, thus determining the preferable reaction path from $\mathrm{A}$ and $\mathrm{B}$ isomers. For the favorable reactions from both $\mathrm{A}$ and $\mathrm{B}$, it is chirality at the $\alpha$-C side that leads to the different kinetic results and product distributions. Rigidity implies that adsorption becomes dominated by the large aryl rings, in the form of the sergeants-and-soldiers principle. In addition, it blocks the reactions from the $\beta$-C side at the beginning of the reaction networks. Computed barriers and energies imply that reactions from the B isomer should be faster than those from the $\mathrm{A}$ isomer. We also found that $\beta$-O- 4 bond cleavage would be promoted or accelerated by the unsaturated $\alpha-\mathrm{C}$ side $(\alpha-\mathrm{C}-\mathrm{H}$ and $\alpha-\mathrm{C}-\mathrm{OH}$ breaks ahead) because this would benefit the formation of conjugated products. $\mathrm{Ru}$ has both positive and negative effects on the catalytic behavior. It promotes direct $\beta-\mathrm{O}-4$ bond scission by lowering the reaction barriers via the strengthened metal-O bond and makes it competitive with the first $\mathrm{C}-\mathrm{H}$ or $\mathrm{C}-\mathrm{OH}$ bond scissions. As $\mathrm{Ru}$ has a stronger adsorption toward reactants than $\mathrm{Ni}$, too much $\mathrm{Ru}$ would lead to less active surface sites by covering the intermediates and impede catalysts. Our DFT study rationalizes the complex reaction network of the most abundant $\beta$-O-4 linkage in lignin, showing the role of stereocenters, rigidity, and conjugation in lignin depolymerization on nickel and Ru-doped nickel catalysts.

\section{ASSOCIATED CONTENT}

\section{S Supporting Information}

Structures and their coordinates, decomposition networks, computed adsorption energies of closed-shell structures, reaction barriers, reaction energies, energy profiles, stability calculation details, and equations for solvation correction (PDF) 


\section{AUTHOR INFORMATION}

\section{Corresponding Authors}

*E-mail: qli@iciq.es. Phone: +34 977920237. Fax: +34 977920231.

*E-mail:nlopez@iciq.es.

ORCID $\odot$

Qiang Li: 0000-0001-5568-2334

Núria López: 0000-0001-9150-5941

\section{Notes}

The authors declare no competing financial interest.

\section{ACKNOWLEDGMENTS}

The authors thank MINECO (CTQ2015-68770-R) for financial support and the Barcelona Supercomputing Centre (BSC-RES) for providing generous computer resources via Centro de Supercomputación y Visualización de Madrid, Universidad Politécnica de Madrid. The authors also appreciate the kind discussion with Dr. Frank Abild-Pedersen from SLAC.

\section{REFERENCES}

(1) Perlack, R. D.; Wright, L. L.; Turhollow, A. F.; Graham, R. L.; Stokes, B. J.; Erbach, D. C. Biomass as Feedstock for a Bioenergy and Bioproducts Industry: The Technical Feasibility of a Billion-ton Annual Supply. Technical Report; U.S. Department of Energy: Washington, DC, 2005.

(2) Zakzeski, J.; Bruijnincx, P. C.; Jongerius, A. L.; Weckhuysen, B. M. The Catalytic Valorization of Lignin for the Production of Renewable Chemicals. Chem. Rev. 2010, 110, 3552-3599.

(3) Li, C.; Zhao, X.; Wang, A.; Huber, G. W.; Zhang, T. Catalytic Transformation of Lignin for the Production of Chemicals and Fuels. Chem. Rev. 2015, 115, 11559-11624.

(4) Behling, R.; Valange, S.; Chatel, G. Heterogeneous Catalytic Oxidation for Lignin Valorization into Valuable Chemicals: What Results? What Limitations? What Trends? Green Chem. 2016, 18, 1839-1854.

(5) Thielemans, W.; Can, E.; Morye, S.; Wool, R. Novel Applications of Lignin in Composite Materials. J. Appl. Polym. Sci. 2002, 83, 323331.

(6) Delidovich, I.; Hausoul, P. J.; Deng, L.; Pfützenreuter, R.; Rose, M.; Palkovits, R. Alternative Monomers Based on Lignocellulose and Their Use for Polymer Production. Chem. Rev. 2016, 116, 1540-1599.

(7) Calvo-Flores, F. G.; Dobado, J. A. Lignin as Renewable Raw Material. ChemSusChem 2010, 3, 1227-1235.

(8) Kai, D.; Tan, M. J.; Chee, P. L.; Chua, Y. K.; Yap, Y. L.; Loh, X. J. Towards Lignin-Based Functional Materials in a Sustainable World. Green Chem. 2016, 18, 1175-1200.

(9) Ragauskas, A. J.; Beckham, G. T.; Biddy, M. J.; Chandra, R; Chen, F.; Davis, M. F.; Davison, B. H.; Dixon, R. A.; Gilna, P.; Keller, M.; Langan, P.; Naskar, A. K.; Saddler, J. N.; Tschaplinski, T. J.; Tuskan, G. A.; Wyman, C. E. Lignin Valorization: Improving Lignin Processing in the Biorefinery. Science 2014, 344, 1246843.

(10) Alonso, D. M.; Hakim, S. H.; Zhou, S.; Won, W.; Hosseinaei, O.; Tao, J.; Garcia-Negron, V.; Motagamwala, A. H.; Mellmer, M. A.; Huang, K.; Houtman, C. J.; Labbé, N.; Harper, D. P.; Maravelias, C.; Runge, T.; Dumesic, J. A. Increasing the Revenue from Lignocellulosic Biomass: Maximizing Feedstock Utilization. Sci. Adv. 2017, 3, No. e1603301.

(11) Schutyser, W.; Renders, T.; Van den Bosch, S.; Koelewijn, S.-F.; Beckham, G.; Sels, B. F. Chemicals from Lignin: An Interplay of Lignocellulose Fractionation, Depolymerisation, and Upgrading. Chem. Soc. Rev. 2018, 47, 852-908.

(12) Chakar, F. S.; Ragauskas, A. J. Review of Current and Future Softwood Kraft Lignin Process Chemistry. Ind. Crops Prod. 2004, 20, $131-141$.
(13) Roberts, V.; Stein, V.; Reiner, T.; Lemonidou, A.; Li, X.; Lercher, J. A. Towards Quantitative Catalytic Lignin Depolymerization. Chem. Eur. J. 2011, 17, 5939-5948.

(14) Sergeev, A. G.; Hartwig, J. F. Selective, Nickel-Catalyzed Hydrogenolysis of Aryl Ethers. Science 2011, 332, 439-443.

(15) Chen, L.; Korányi, T. I.; Hensen, E. J. Transition Metal (Ti, Mo, $\mathrm{Nb}, \mathrm{W})$ Nitride Catalysts for Lignin Depolymerisation. Chem. Commun. 2016, 52, 9375-9378.

(16) Molinari, V.; Clavel, G.; Graglia, M.; Antonietti, M.; Esposito, D. Mild Continuous Hydrogenolysis of Kraft Lignin over Titanium Nitride-Nickel Catalyst. ACS Catal. 2016, 6, 1663-1670.

(17) Song, Q.; Wang, F.; Xu, J. Hydrogenolysis of Lignosulfonate into Phenols over Heterogeneous Nickel Catalysts. Chem. Commun. 2012, 48, 7019-7021.

(18) Zhang, J.; Teo, J.; Chen, X.; Asakura, H.; Tanaka, T.; Teramura, K.; Yan, N. A Series of NiM ( $M=R u, R h$, and Pd) Bimetallic Catalysts for Effective Lignin Hydrogenolysis in Water. ACS Catal. 2014, 4, 1574-1583.

(19) Zhang, J. W.; Cai, Y.; Lu, G. P.; Cai, C. Facile and Selective Hydrogenolysis of $\beta$-O-4 Linkages in Lignin Catalyzed by $\mathrm{Pd}-\mathrm{Ni}$ Bimetallic Nanoparticles Supported on $\mathrm{ZrO}_{2}$. Green Chem. 2016, 18, 6229-6235.

(20) Lu, J.; Wang, M.; Zhang, X.; Heyden, A.; Wang, F. $\beta$-O-4 Bond Cleavage Mechanism for Lignin Model Compounds over Pd Catalysts Identified by Combination of First-principles Calculations and Experiments. ACS Catal. 2016, 6, 5589-5598.

(21) Zhang, C.; Li, H.; Lu, J.; Zhang, X.; MacArthur, K. E.; Heggen, M.; Wang, F. Promoting Lignin Depolymerization and Restraining the Condensation via an Oxidation-Hydrogenation Strategy. ACS Catal. 2017, 7, 3419-3429.

(22) Ould Hamou, C. A.; Réocreux, R.; Sautet, P.; Michel, C.; Giorgi, J. B. Adsorption and Decomposition of a Lignin $\beta$-O-4 Linkage Model, 2-Phenoxyethanol, on $\mathrm{Pt}$ (111): Combination of Experiments and First-Principles Calculations. J. Phys. Chem. C 2017, 121, 9889-9900.

(23) Li, Q.; García-Muelas, R.; López, N. Microkinetics of Alcohol Reforming for $\mathrm{H}_{2}$ Production from a FAIR Density Functional Theory Database. Nat. Commun. 2018, 9, 526.

(24) Calvo-Flores, F. G.; Dobado, J. A.; Isac-García, J.; MartíMartínez, F. J. Lignin and Lignans as Renewable Raw Materials: Chemistry, Technology and Applications; John Wiley \& Sons, 2015.

(25) He, J.; Zhao, C.; Lercher, J. A. Ni-Catalyzed Cleavage of Aryl Ethers in the Aqueous Phase. J. Am. Chem. Soc. 2012, 134, 2076820775 .

(26) Kresse, G.; Furthmüller, J. Efficiency of ab-initio Total Energy Calculations for Metals and Semiconductors Using a Plane-wave Basis Set. Comput. Mater. Sci. 1996, 6, 15-50.

(27) Kresse, G.; Furthmüller, J. Efficient Iterative Schemes for $a b$ initio Total-energy Calculations Using a Plane-wave Basis Set. Phys. Rev. B: Condens. Matter Mater. Phys. 1996, 54, 11169-11186.

(28) Perdew, J. P.; Burke, K.; Ernzerhof, M. Generalized Gradient Approximation Made Simple. Phys. Rev. Lett. 1996, 77, 3865-3868.

(29) Grimme, S. SemiEmpirical GGA-type Density Functional Constructed with a Long-range Dispersion Correction. J. Comput. Chem. 2006, 27, 1787-1799.

(30) Bučko, T.; Hafner, J.; Lebegue, S.; Angyán, J. G. Improved Description of the Structure of Molecular and Layered Crystals: $A b$ initio DFT Calculations with van der Waals Corrections. J. Phys. Chem. A 2010, 114, 11814-11824.

(31) Almora-Barrios, N.; Carchini, G.; Błoński, P.; López, N. Costless Derivation of Dispersion Coefficients for Metal Surfaces. J. Chem. Theory Comput. 2014, 10, 5002-5009.

(32) Blöchl, P. E. Projector Augmented-wave Method. Phys. Rev. B: Condens. Matter Mater. Phys. 1994, 50, 17953-17979.

(33) Kresse, G.; Joubert, D. From Ultrasoft PseudoPotentials to the Projector Augmented-wave Method. Phys. Rev. B: Condens. Matter Mater. Phys. 1999, 59, 1758-1775.

(34) Monkhorst, H. J.; Pack, J. D. Special Points for Brillouin-zone Integrations. Phys. Rev. B 1976, 13, 5188-5192. 
(35) Lide, D. CRC Handbook of Chemistry and Physics, 84th ed.; CRC Press LLC: Boca Raton, FL, 2003-2004; pp 12(19-21).

(36) Makov, G.; Payne, M. C. Periodic Boundary Conditions in $a b$ initio Calculations. Phys. Rev. B: Condens. Matter Mater. Phys. 1995, 51, 4014-4022.

(37) Nørskov, J. K.; Studt, F.; Abild-Pedersen, F.; Bligaard, T. Fundamental Concepts in Heterogeneous Catalysis; John Wiley \& Sons, 2014.

(38) Henkelman, G.; Uberuaga, B. P.; Jónsson, H. A Climbing Image Nudged Elastic Band Method for Finding Saddle Points and Minimum Energy Paths. J. Chem. Phys. 2000, 113, 9901-9904.

(39) Heyden, A.; Bell, A. T.; Keil, F. J. Efficient Methods for Finding Transition States in Chemical Reactions: Comparison of Improved Dimer Method and Partitioned Rational Function Optimization Method. J. Chem. Phys. 2005, 123, 224101.

(40) Garcia-Ratés, M.; López, N. Multigrid-Based Methodology for Implicit Solvation Models in Periodic DFT. J. Chem. Theory Comput. 2016, 12, 1331-1341.

(41) Garcia-Ratés, M.; García-Muelas, R.; López, N. Solvation Effects on Methanol Decomposition on $\mathrm{Pd}(111), \operatorname{Pt}(111)$ and $\mathrm{Ru}(0001)$. J. Phys. Chem. C 2017, 121, 13803-13809.

(42) López, N.; Vargas-Fuentes, C. Promoters in the Hydrogenation of Alkynes in Mixtures: Insights from Density Functional Theory. Chem. Commun. 2012, 48, 1379-1391.

(43) Soto-Verdugo, V.; Metiu, H. Segregation at the Surface of an $\mathrm{Au} / \mathrm{Pd}$ Alloy Exposed to CO. Surf. Sci. 2007, 601, 5332-5339.

(44) Álvarez-Moreno, M.; De Graaf, C.; López, N.; Maseras, F.; Poblet, J. M.; Bo, C. Managing the Computational Chemistry Big Data Problem: The ioChem-BD Platform. J. Chem. Inf. Model. 2015, 55, 95-103.

(45) Li, Q.; López, N. Dataset for lignin decomposition on $\mathrm{Ni}$ and Ru-Ni. DOI: 10.19061/iochem-bd-1-52.

(46) Green, M. M.; Reidy, M. P.; Johnson, R. D.; Darling, G.; O'Leary, D. J.; Willson, G. Macromolecular StereoChemistry: The Out-of-proportion Influence of Optically Active Comonomers on the Conformational Characteristics of Polyisocyanates. The Sergeants and Soldiers Experiment. J. Am. Chem. Soc. 1989, 111, 6452-6454.

(47) Wang, S.; Vorotnikov, V.; Vlachos, D. G. Coverage-induced Conformational Effects on Activity and Selectivity: Hydrogenation and Decarbonylation of Furfural on Pd(111). ACS Catal. 2015, 5, 104112 .

(48) Besora, M.; Vidossich, P.; Lledós, A.; Ujaque, G.; Maseras, F. Calculation of Reaction Free Energies in Solution: A Comparison of Current Approaches. J. Phys. Chem. A 2018, 122, 1392-1399.

(49) Mellmer, M. A.; Sanpitakseree, C.; Demir, B.; Bai, P.; Ma, K.; Neurock, M.; Dumesic, J. A. Solvent-enabled Control of Reactivity for Liquid-phase Reactions of Biomass-derived Compounds. Nat. Catal. 2018, 1, 199-207.

(50) Salciccioli, M.; Vlachos, D. G. Kinetic Modeling of Pt Catalyzed and Computation-driven Catalyst Discovery for Ethylene Glycol Decomposition. ACS Catal. 2011, 1, 1246-1256.

(51) Bellarosa, L.; García-Muelas, R.; Revilla-López, G.; López, N. Diversity at the Water-Metal Interface: Metal, Water Thickness, and Confinement Effects. ACS Cent. Sci. 2016, 2, 109-116.

(52) Dwivedi, A. D.; Rai, R. K.; Gupta, K.; Singh, S. K. Catalytic Hydrogenation of Arenes in Water over in situ Generated Ruthenium Nanoparticles Immobilized on Carbon. Chem CatChem 2017, 9, 19301938. 